\title{
Correlation of Risk Factors with Different Reporting Categories of Fine Needle Aspiration Cytology (FNAC) of Palpable Breast Lumps
}

\author{
Muhammad Mudassar, ${ }^{1}$ Muhammad Awais, ${ }^{2}$ Nadeem Ikram, ${ }^{3}$ Sadia Hameed, ${ }^{4}$ Shazia Aslam, ${ }^{5}$ Farhan Abbas Baloch 6
}

\begin{abstract}
${ }^{1}$ Department of Pathology, Batterjee Medical College, Jeddah-Saudi Arabia, ${ }^{2}$ Department of Microbiology, Batterjee Medical College, Jeddah-Saudi Arabia, ${ }^{3}$ Department of Immunology, Batterjee Medical College, Jeddah-Saudi Arabia, ${ }^{4,5}$ Department of Pathology, University Medical and Dental College, Faisalabad-Pakistan ${ }^{6}$ Department of Pathology, Pak International Medical College, Peshawar-Pakistan
\end{abstract}

\begin{abstract}
Background: Fine needle aspiration cytology (FNAC) is a well-known and valued technique for estimation of palpable breast masses before any surgery because it is highly sensitive, accurate, specific, and cheap. Most of the time, the risk factors are global, but sometimes there are some local, environmental, ethnic and genetic factors which could be different in different communities. Objective: To study different known risk factors of breast cancer in the population of Faisalabad and correlate it with FNAC categories and track significant factors in the local population. Study Design: Descriptive retrospective study. Settings: Meezan lab and University Medical and Dental College, Faisalabad Pakistan. Duration: June 2014- June 2019 (5 years). Methodology: A total of 1928 females with palpable breast lumps. FNA was done using a 23-gauge needle and results were interpreted by pathologists for adequacy and cellularity. Final cytological diagnoses were categorized as per United Kingdom National Health Services Breast Screening Program (NHSBSP) guidelines. The benign and malignant categories were correlated with risk factors like Age, Obesity, Genetic factors/ family history, contraceptives use, menstrual history, etc. All the collected information was analyzed using SPSS version-24. Frequency and percentages were measured for variables like FNAC categories and age. Risk factors were compared with benign and malignant categories and Chisquare test was used for correlation. Results: Out of 1928 cases, 469 (24.3\%) were C5 (Malignant), and 1234 (64\%) were C2 (Benign). For practical and treatment purposes both C2 and C3 were considered benign, comprising of $1357(70.4 \%)$ cases and C4 and C5 were taken as malignant comprising of 571 cases $(29.6 \%)$. Correlation of risk factors with Breast cancer revealed that following parameters were significant with $P$ valve $<0.05$; Age 40-100 years, Obesity, Breast feeding, Active smoking, Married couple, Post menopause, Contraceptives not used and Malignant tumor history. On the other hand, Family history and radiation exposure were not found significant in the current study. Conclusion: Age $>40$, obesity, active smoking, post-menopausal status, breast feeding, marital status and malignant tumor history are the significant risk factors which are associated with breast FNAC categories of $\mathrm{C} 4$ and $\mathrm{C} 5$.
\end{abstract}

Keywords: Breast FNAC, Age, Obesity, Smoking, Post-menopause, Contraceptive use, Breast feeding, Family history.

Corresponding Author Submitted for Publication: 06-02-2020 Accepted for Publication: 25-03-2020

Dr. Sadia Hameed, Professor \& Head, Pathology Department, University Medical and Dental College, Faisalabad-Pakistan.

Email: sadia.hameed@tuf.edu.pk

Citation: Mudassar M, Awais M, Ikram N, Hameed S, Aslam S, Baloch FA. Correlation of Risk Factors with Different Reporting Categories of Fine Needle Aspiration Cytology (FNAC) of Palpable Breast Lumps. APMC 2020;14(2):173-8.

DOI: $10.29054 / A P M C / 2020.864$

\section{INTRODUCTION}

Throughout the world breast cancer secures $2^{\text {nd }}$ place among cancers in females. In 2010, 1.05 million new cases were reported. Since 1960 there is an increase in incidence of breast cancer.

Across different nations incidence rate was showing a 4 to 5 time's variation, being highest in Western Europe and North America, and lowest in Asia. In India the highest incidence rate is observed in Mumbai with other big cities also showing an increasing trend. According to registered data, one can easily estimate that every year in India there will be about 800,000 new cases of breast cancer. ${ }^{1}$ Worldwide more than 1.5 million are diagnosed with breast cancer each year, which is about $25 \%$ of all women suffering from cancer. ${ }^{2}$ It is also observed that number of breast cancer cases is 100 folds more in women than in men. In year 2015, 570,000 people died of breast cancer worldwide.2,3

Triple assessment methodology is adopted for precise diagnosis of breast cancers that involve clinical, imaging and pathological examinations. In pathologic assessment one of the most commonly used techniques is 'Fine needle aspiration cytology' (FNAC). It is a well-known and valued technique for estimation of breast masses before any surgery because it is highly sensitive, accurate, specific, time saving and cheap. ${ }^{4-7}$ Waghmare et al reported sensitivity, specificity, positive predictive value, negative predictive value; efficiency was $88.24 \%, 100 \%, 100 \%, 93.26 \%$, and $95.22 \%$ respectively. ${ }^{8}$ While David et al found out the sensitivity of $99.4 \%$, the specificity of $100 \%$, positive predictive value $100 \%$ and negative predictive value of $66.7 \%$ with accuracy of $86.3 \%{ }^{7}$ This approach has gained great confidence because it can prevent the traditional biopsy involving excision, when all three components of the triple test are conclusively negative or positive. . $^{9-11}$

Many risk factors are blamed for the causation and increased incidence of this tumor. Risk factor can be simply defined as something that will enhance the chance of development of an ailment. 
Different population based studies over the past many years indicated that new cases of breast cancer (about 20\% to 30\%) are because of certain risk factors, noticeably age (above 40 years, and at menopause), female gender, family history (cancer in immediate relatives, diseases of mammary gland), reproductive factors (menarche at an early stage, menopause at a late age, child bearing after 35 years of age, nulli-parity, low parity), high estrogen level in body, no breast feeding history, contraception, hormonal treatment and living style including alcohol consumption, meal high in fatty content, poor physical activity, obesity and smoking. ${ }^{12-17}$

Whenever any patient is diagnosed with breast cancer, they always want to know why they got this cancer, in other words, they want to know about etiology and risk factors. Rationale of our study is that, even the risk factors are usually global, but there are some local, environmental, ethnic and genetic factors which could be different in different communities. Faisalabad, $3^{\text {rd }}$ largest city of Pakistan, is an industrial city with diverse population and significant cancer incidence..$^{18,19}$

So, do all the global risk factors are also significant in local population, or there is some deviation or variation among them? Based on above reasons, a numbers of risk factors were analyzed to know their impact and significance in the population. Objective of the study was to correlate risk factors with different reporting categories of fine needle aspiration cytology (FNAC) of palpable breast lumps, presenting at Faisalabad, Pakistan.

\section{METHODOLOGY}

Study Design: Descriptive retrospective study.

Settings: Meezan lab (Pvt) and University Medical and Dental College, Faisalabad Pakistan.

Duration: June 2014- June 2019 (5 years).

Sample Technique: Non-probability consecutive sampling.

Sample Size: A total of 1928 females were included.

Inclusion Criteria: All females who presented with palpable breast mass during the study period.

Exclusion Criteria: Inadequate or insufficient samples, Patients with history of past or current chemotherapy and Patient who did not give consent were excluded.

Data Collection Procedure: Patients who fulfilled the exclusion and inclusion criteria were selected. A designed proforma was used to collect data of patients. Risk factors like Age, Life style and Obesity, Physical activity, Genetic factors/ family history, History of using contraceptives, menstrual history, history of previous breast lesions, Radiation exposure, Exposure to smoking (active or passive smoker), Marital status and history of breast feeding were recorded in the proforma, as and when available. FNA was done using a 23-gauge needle and disposable $5 \mathrm{~mL}$ disposable syringe of Becton and Dickinson Pakistan (Pvt) for each prick and for each patient. No local anesthetic was used, and the needle was inserted into the palpable lesions, either once or twice depending upon the size of the nodule. Cellular material was aspirated into a syringe and expelled onto slides. Four to five slides were prepared for each patient.

A small or medium sized drop of aspirate was put near the frosted end of a slide that was placed on a table. A second slide was used to spread the aspirated material in the same manner used to prepare a peripheral blood smear. Air dried smears were stained with the Diff-Quik method, the FNA was interpreted by the pathologists for adequacy and cellularity. If needed, repeat FNA was done to ensure adequacy and afterwards a preliminary cytologic diagnosis were rendered. Remaining smears were wet fixed in 95\% methanol, and stained with Hematoxylin \& Eosin $(H \& E)$, and Papanicolaou stains. The Final cytological diagnoses were then categorized into one of five diagnostic categories in accordance with the recommendations of the United Kingdom National Health Services Breast Screening Program (NHSBSP). ${ }^{7}$

$\mathrm{CI}$ - Insufficient cells for cytological analysis

C2 - Cells present all benign; no suspicious features

C3 - Cells suspicious but probably benign,

C4 - Cells suspicious but probably malignant

C5 - Definitely malignant.

For comparison purposes, we combined category 2 and 3 and regrouped as "Benign" and C4 and C5 as "malignant", as practiced by some other studies. ${ }^{20}$ All cases which were $\mathrm{C} 1$ or Insufficient for cytological diagnosis, they were repeated 2 to 4 times, until we got an adequate smears. If even after multiple attempts, the adequacy was not achieved; those cases were excluded from our study.

Data Analysis: All the collected information was entered and analyzed using SPSS version 24 . Frequency and percentages were measured for variables like FNAC categories and age. Risk factors were compared with benign and malignant categories and $P$ values were also calculated, while correlation was seen by Chi-square test.

\section{RESULTS}

Out of 1928 cases, 469 (24.3\%) were C5 (Malignant), and 1234 (64\%) were C2 (Benign). For practical and treatment purposes both $\mathrm{C} 2$ and $\mathrm{C} 3$ were considered benign, comprising of 1357 (70.4\%) cases and C4 and C5 were taken as malignant comprising of 571 cases $(29.6 \%)$. Correlation of risk factors with Breast cancer revealed that following parameters were significant with $P$ valve $<0.05$; Age $40-100$ years, Obesity, Breast feeding done, Active smoking, Married couple, Post menopause, Contraceptives not used and Malignant tumor history. On the other hand, Family history and radiation exposure were not found significant in the current study. (Table2). Photomicrographs of the $\mathrm{C} 2, \mathrm{C} 4$ and $\mathrm{C} 5$ lesions are shown from Figure 1 to 4 . 
Table 1: Frequency of different categories on FNAC of palpable breast mass

\begin{tabular}{|l|c|c|c|c|}
\hline \multicolumn{1}{|c|}{ FNAC Categories } & Frequency & Percent (\%) & Combined Frequency & Combined Percent (\%) \\
\cline { 1 - 2 } C-2: Benign & 1234 & 64.0 & \multirow{2}{*}{1357} & \multirow{2}{*}{70.4} \\
\cline { 1 - 2 } C-3: Atypical, probably benign & 123 & 6.4 & \multirow{2}{*}{571} & \multirow{2}{*}{29.6} \\
\hline C-4: Suspicious, favor malignancy & 102 & 5.3 & 1928 & 100.0 \\
\hline C-5: Malignant & 469 & 24.3 & 100.0 & \\
\hline Total & 1928 & & \\
\hline
\end{tabular}

Table 2: Correlation of risk factors with benign and malignant breast FNAC categories

\begin{tabular}{|c|c|c|c|c|c|c|}
\hline Risk factors & Para meters & $\begin{array}{c}\text { Benign Breast FNAC } \\
\text { categories }(\mathrm{C} 2+\mathrm{C} 3)\end{array}$ & $\begin{array}{l}\text { Malignant Breast } \\
\text { FNAC categories } \\
\text { (C4+C5) }\end{array}$ & $\begin{array}{l}\text { Total number } \\
\text { of cases }(N=n)\end{array}$ & Chi-Square & P-Valve \\
\hline \multirow{2}{*}{ Age } & $0-39$ years & $1031^{*}(87.4 \%)$ & $149(12.6 \%)$ & $n=1180$ & \multirow{2}{*}{421.138} & \multirow{2}{*}{0.000} \\
\hline & $40-100$ years & $326(43.6 \%)$ & $422^{*}(56.4 \%)$ & $n=728$ & & \\
\hline \multirow{2}{*}{ Obesity } & Normal weight & $1204^{*}(72.7 \%)$ & $452(27.3 \%)$ & $n=1656$ & \multirow{2}{*}{31.136} & \multirow{2}{*}{0.000} \\
\hline & Obese & $148(55.8 \%)$ & $117^{*}(44.2 \%)$ & $\mathrm{n}=265$ & & \\
\hline \multirow{2}{*}{ Breast feeding } & Feeding done & $768(61.9 \%)$ & $473^{*}(38.1 \%)$ & $n=1241$ & \multirow{2}{*}{4.262} & \multirow{2}{*}{0.039} \\
\hline & Feeding not done & $79^{*}(71.8 \%)$ & $31(28.2 \%)$ & $n=110$ & & \\
\hline \multirow{2}{*}{$\begin{array}{l}\text { Radiation } \\
\text { exposure }\end{array}$} & no exposure & $1290(69.7 \%)$ & $562(30.3 \%)$ & $n=1852$ & \multirow{2}{*}{0.729} & \multirow{2}{*}{0.393} \\
\hline & Exposed & $2(50 \%)$ & $2(50 \%)$ & $\mathrm{n}=4$ & & \\
\hline \multirow{2}{*}{ Smoking } & No active smoking & $1216^{*}(70.9 \%)$ & $498(29.1 \%)$ & $\mathrm{n}=1714$ & \multirow{2}{*}{12.289} & \multirow{2}{*}{0.000} \\
\hline & Active smoking & $7(35.0 \%)$ & $13^{*}(65.0 \%)$ & $\mathrm{n}=20$ & & \\
\hline \multirow{2}{*}{ Marital status } & Married & $982(63.8 \%)$ & $557^{*}(36.2 \%)$ & $n=1539$ & \multirow{2}{*}{160.454} & \multirow{2}{*}{0.000} \\
\hline & Unmarried & $375^{*}(96.6 \%)$ & $13(3.4 \%)$ & $n=388$ & & \\
\hline \multirow{2}{*}{ Menopause } & Pre-menopause & $1209^{*}(78.8 \%)$ & $325(21.2 \%)$ & $n=1534$ & \multirow{2}{*}{259.793} & \multirow{2}{*}{0.000} \\
\hline & Post-menopause & $143(37.0 \%)$ & $244^{*}(63.0 \%)$ & $n=387$ & & \\
\hline \multirow{2}{*}{ Family History } & Negative & $1235(70.3 \%)$ & $523(29.7 \%)$ & $n=1758$ & \multirow{2}{*}{0.022} & \multirow{2}{*}{0.882} \\
\hline & Positive & $114(70.8 \%)$ & $47(29.2 \%)$ & $n=161$ & & \\
\hline \multirow{2}{*}{ Contraceptives } & Not used & $1225(69.4 \%)$ & $540 *(30.6 \%)$ & $n=1765$ & \multirow{2}{*}{8.643} & \multirow{2}{*}{0.003} \\
\hline & Used (Oral, Inj. Or both) & $122^{*}(80.8 \%)$ & $29(19.2 \%)$ & $n=151$ & & \\
\hline \multirow{2}{*}{$\begin{array}{l}\text { Malignant tumor } \\
\text { history }\end{array}$} & No history & $1292^{*}(69.8 \%)$ & $560(30.2 \%)$ & $n=1852$ & \multirow{2}{*}{2.715} & \multirow{2}{*}{0.099} \\
\hline & Present & $4(44.4 \%)$ & $5^{*}(55.6 \%)$ & $n=9$ & & \\
\hline
\end{tabular}

Note: $P$ valve $<0.05$ is taken as significant.

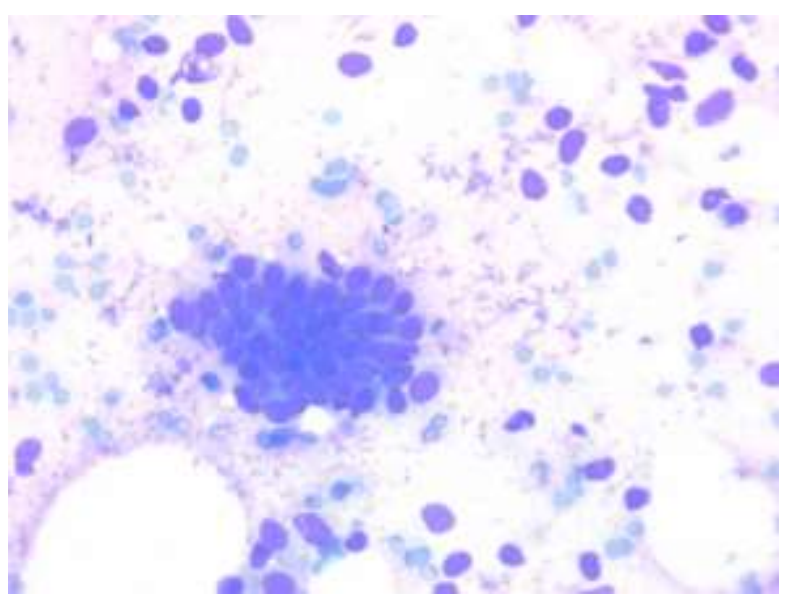

Figure 1: High power view of a smear from C2 lesion revealing cohesive group of ductal epithelial \& myoepithelial cells

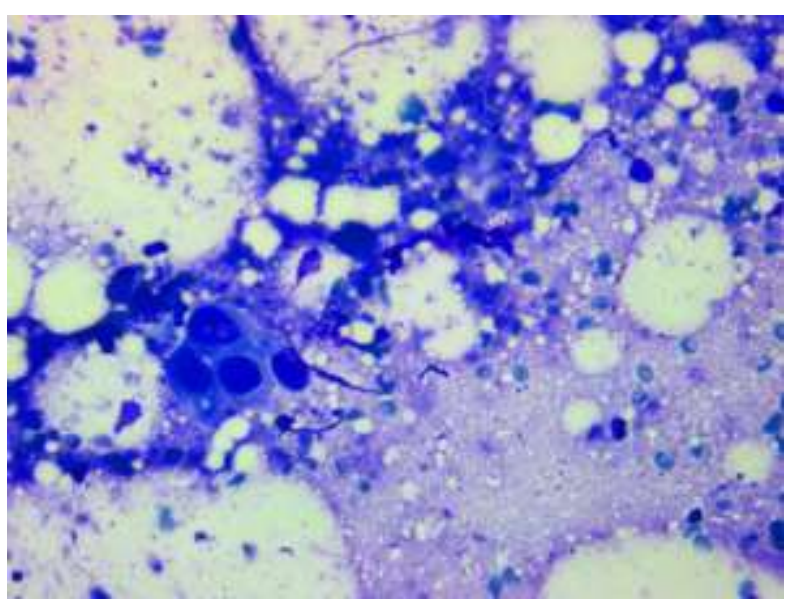

Figure 2: C4 lesion (suspicious looking cells, probably malignant), 40x magnification 


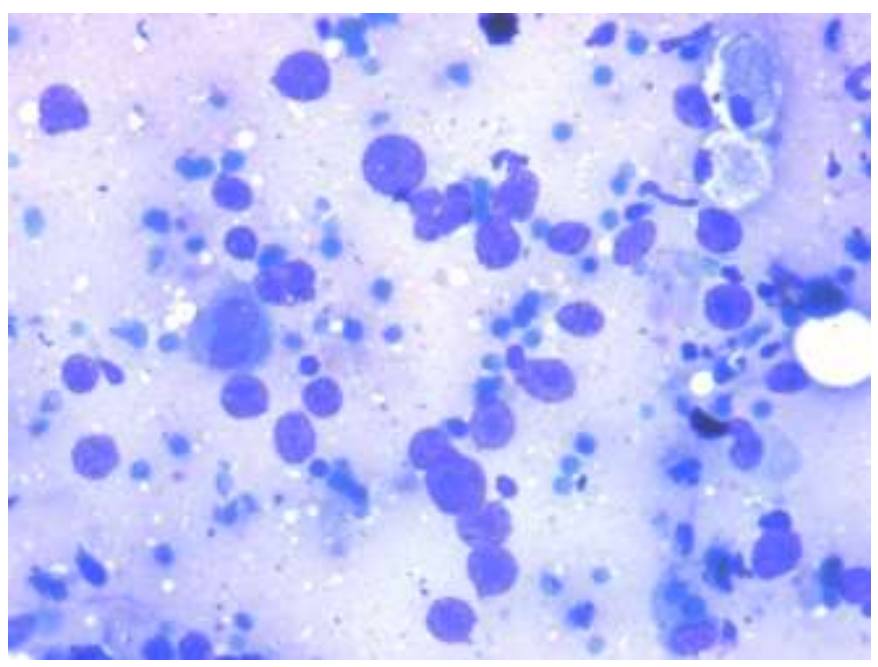

Figure 3: C5, Malignant cells, at 40x magnification

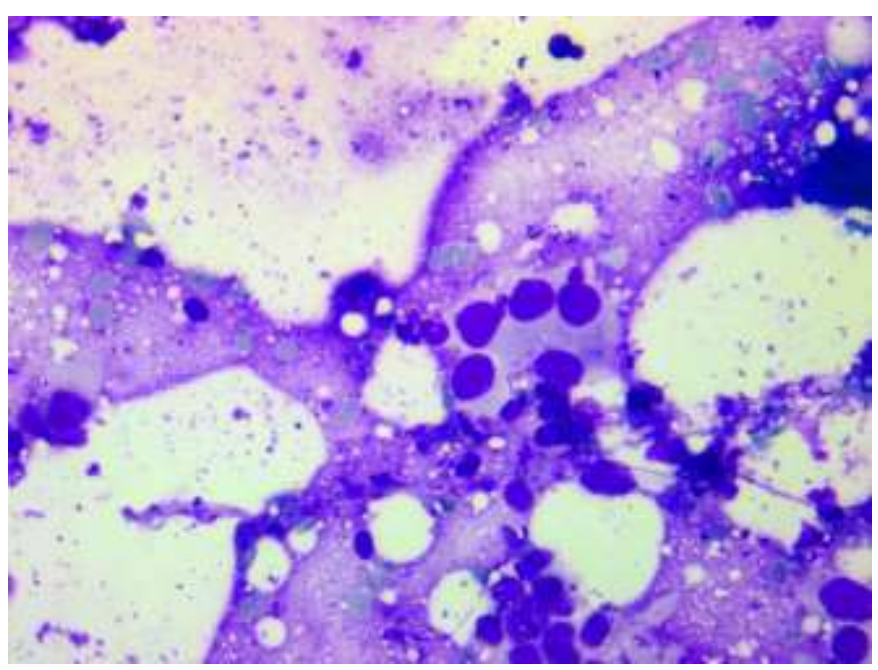

Figure 4: C5 lesion, taken at 40x magnification

\section{DISCUSSION}

It is observed that with increasing age, risk of developing breast cancer is also high. ${ }^{1}$ In an epidemiological study, data pointed out that women in the age ranging from $50-69$ years showed $50 \%$ of such breast cancers. ${ }^{21}$ In American population, all breast cancer related mortality (about 99.3\% and 71.2\%) in year 2016 were seen in women which are over 40 and 60 years of age. ${ }^{3}$ In our study we also found that $56.4 \%$ of women diagnosed as malignant breast cancer were of age $>40$ years of age, and $87.4 \%$ females who were diagnosed as $\mathrm{C} 2+\mathrm{C} 3$ were of age < 40 years with a $P$ value of 0.00 and Chi-square of 421.138 . (See table 2)

A number of lifestyles are implicated in increasing the risk of breast cancer like intake of high fatty meal, utilization of contraceptive pills, breast feeding behavior and smoking. Higher intake of fats (especially the saturated fat) in the diet of western world in recent times has resulted in gaining enormous weight (obesity) that in turn is associated with poor prognosis and death in patients of breast cancer. ${ }^{16}$ Also a number of flavoring agents and preservatives present in processed foods may also stimulate cancer developing process. ${ }^{21,22}$ In our study we also found a significant high percentage of obese females presenting with breast cancer i.e. $44.2 \%$ with $P$ value of 0.00 . (See table 2). Evidence suggests that regular physical activity, with a frequency of 3-5 times a week decreases the risk of breast cancer by $20-40 \%$, strengthen the immunological system, improves general fitness and the quality of life. ${ }^{23,24}$ With this correlation, there is a high risk of breast cancer when observed in postmenopausal women. ${ }^{22,25}$ Tan et al reported that postmenopausal women had a $52 \%$ increased risk of breast cancer after adjusting for demographics and other risk factors. ${ }^{26}$ Our results were also consistent with this finding since $63 \%$ of breast cancer was seen in post-menopausal women with Chi-square and $P$ value of 259.793 and 0.000 respectively (See table 2 ).

Use of oral contraceptives is very common since 1960's and various formulations are available that are regularly improved to minimize the side effects. There are controversial results in the literature regarding their use and breast cancer causation. Some studies mentioned that oral contraceptives being a main source of exogenous estrogen can increase the risk of breast cancer. ${ }^{17}$ However, it is found that risks of breast cancer do not increase in women who stopped using them for a time period of more than 10 years. ${ }^{27}$ Marchbanks et al concluded current or former oral-contraceptive use was not associated with a significantly increased risk of breast cancer. ${ }^{28}$ In our study, we also found that only 29 females with breast cancer used contraception in any form, while 540 females with breast cancer did not used any form of contraception. Rather there were $80.8 \%$ of females with benign breast lesion, who used contraception with a significant $P$ valve (0.003). (See table 2 ). It is consistent with other recent studies. ${ }^{29}$ One of the main sources of exogenous estrogen is hormone replacement therapy that can increase the breast cancer risk. A UK base study called as 'The Million Women Study' stated that there is a relative risk (RR) of 1.66 between women who are presently using the hormone replacement therapy and those who never used it. ${ }^{30}$

Studies conducted on the breast fluid from non-lactating women revealed the presence of mutation causing agents that are present in the cigarette smoke. In women there are much higher chances of acquiring breast cancer that not only smoke but also consume alcohol simultaneously ${ }^{31}$ or they smoke and used contraceptives simultaneously. ${ }^{25}$ Up till now, different gathered facts clearly indicate that female, who smoke in young ages, are more prone in getting breast cancer. ${ }^{32}$ Our study is also consistent with above mentioned studies and showed significant relationship of active smoking with breast malignancies $(\mathrm{P}=0.000)$ (See table 2).

If close relatives (mother or sister) of a woman are diagnosed with breast cancer, such women are more likely to acquire it. This hypothesis was proved by a group study of more than 113,000 women in United Kingdom. It was found that women having 1 st immediate relative with breast cancer are at a higher risk of getting the cancer (about 1.75 times higher) as compared to women with no relative affected with breast cancer. Furthermore, this risk increases to a value of 2.5 times and even higher, if women have 2 or more immediate relatives suffering 
from breast cancer. The hereditary predisposition is somewhat credited to breast cancer genes (BRCA-1 and BRCA-2). ${ }^{33}$ In our study, we found a non-significant relationship ( $P=0.882)$ regarding positive family history and breast cancer risk. This is consistent with other studies, who found BRCA-1 mutations in a significant population even without family history, ${ }^{34}$ proving that family history alone is not a sufficient risk factor to be associated with breast cancer.

As mentioned earlier, various reproductive factors are held responsible in increasing the risk of breast cancer. Different studies showed that there is 3\% more risk of developing breast cancer with every one-year delay in menopause. On the other hand, risk of breast cancer decreases by $5 \%$ or $10 \%$ with every one year delay in menarche and every additional birth, respectively. ${ }^{17,27}$ Women who are exposed to estrogens for longer period (as in case of early menarche) have high risk of developing breast cancer. As a 10\% decrease has been observed in occurrence of risk of breast cancer due to each delay of menarche by two years, so women in whom menarche appeared at an age before 12 years, are exposed to a much higher level of estrogens during each menstrual cycle than those with menarche occurring at an age after 13 years. ${ }^{21}$ Some of the reproductive factors lower the risk of breast cancer like early pregnancy and delivery on due date, also extended breast feeding has same protective effects. According to an epidemiologic data, the risk of cancer decreases by $4.3 \%$ with each year of breast feeding. ${ }^{35}$ However, in our study we found that females who breast fed their infants had $38.1 \%$ risk of breast cancer while who did not do breast feeding had $28.2 \%$ of breast cancer. Antony et al also found that there was no statistical difference between breast feeding and breast cancer ${ }^{1}$. Actually, we could not get data regarding full length of duration and number of pregnancies. Even if females tried for few days or months, it was taken as positive. Moreover, history whether they used formula milk or other milk preparations were not noticed. Evidence suggests that longer the women breast feed, the more they are protected against breast cancer and the lack of or short lifetime duration of breastfeeding makes a major contribution to the high incidence of breast cancer. ${ }^{35}$

Evidence suggests that radiation exposure can increase the chances of breast cancer. ${ }^{36}$ But we found a non-significant relationship of Radiation exposure with breast cancer $(P=0.393)$. Actually only 4 females were subjected to radiations in our study, out of which, 2 got breast malignancy. So probably the insignificance of this parameter could be due to decreases number of cases. Marital status was not found significant in the study by Antony et al ${ }^{1}$. However we found that significant breast malignancies $(P=0.000)$ were seen in married women $(36.2 \%)$ and it was consistent with Norsa'adah et al. ${ }^{37}$

\section{CONCLUSION}

Age $>40$, obesity, active smoking, post-menopausal status, breast feeding, marital status and malignant tumor history are the significant risk factors which are associated with $\mathrm{C} 4$ and $\mathrm{C} 5$ categories on fine needle aspiration cytology (FNAC) of palpable breast lumps of Faisalabad population. On the other hand, risk factors of radiation exposure and family history ware not found significant.

\section{LIMITATIONS}

Other risk factors including Body Mass Index (BMI), alcohol consumption, age at menarche, parity, income and height have been studied by some other studies,,$^{21,38}$ but data for these parameters could not be collected for logistics reason in the current study. Moreover, correlation with histopathology was not available at the time of study. Future studies would be focused on the correction of these limitations.

\section{SUGGESTIONS / RECOMMENDATIONS}

Modification of dietary factors, life style and intake of vitamin D can lead to relative reduction in the risk of breast cancer.

\section{CONFLICT OF INTEREST / DISCLOSURE}

Authors have no conflict of interest.

\section{ACKNOWLEDGEMENTS}

Authors would acknowledge laboratory staff \& IT personal of Meezan laboratory, Faisalabad for technical assistance.

\section{REFERENCES}

1. Antony M, Surakutty B, Vasu T, Chisthi M. Risk factors for breast cancer among Indian women: A case-control study. Niger J Clin Pract. 2018;21(4):436-42.

2. Bernard WS, Christopher PW. World cancer report 2014. World Heal. Organ. 2014;630.

3. Siegel RL, Miller KD, Jemal A. Cancer statistics, 2016. CA Cancer J Clin. 2016;66(1):7-30.

4. Aker F, Gümrükçü G, Onomay BÇ, Erkan M, Gürleyik G, Kiliçołlu $G$, et al. Accuracy of fine-needle aspiration cytology in the diagnosis of breast cancer a single-center retrospective study from Turkey with cytohistological correlation in 733 cases. Diagn. Cytopathol. 2015;43(12):978-86.

5. Daramola AO, Odubanjo MO, Obiajulu FJ, Ikeri NZ, Banjo AAF. Correlation between Fine-Needle Aspiration Cytology and Histology for Palpable Breast Masses in a Nigerian Tertiary Health Institution. Int J Breast Cancer. 2015; 2015.742573.

6. Velu ARK, Srinivasamurthy BC, Rani J. Cytological evaluation of benign breast lesions with histopathological correlation. Indian J. Pathol. Oncol. 2016:3:7.

7. Ibikunle DE, Omotayo JA, Ariyibi OO. Fine needle aspiration cytology of breast lumps with histopathologic correlation in Owo, Ondo State, Nigeria: a five-year review. Ghana Med J. 2017;51(1):1-5.

8. Waghmare R, Sakore S, Rathod S. Fine needle aspiration cytology of breast lesions and correlation with histopathology. Int J Res Med. Sci. 2016;4(1):4416-21.

9. Gaikwad SR, Talpallikar MC, Tapadia JK, Gajakos AS. Diagnostic evaluation of triple test in detection of breast lesions. Int. Surg. J. 2019; 6: 586.

10. Ahmed I, Nazir R, Chaudhary MY, Kundi S. Triple assessment of breast lump. J. Coll. Physicians Surg. Pakistan. 2007; 17: 535-8.

11. Gadhvi AS, Gadhvi UI, Bhimani DA, Rajgor DK. Role of triple assessment modalities in diagnosis of palpable breast lump. Int. J. Res. Med. Sci. 2018; 6: 3435. 
12. Brentnall AR, Cuzick J, Buist DSM, Bowles EJA. Long-Term accuracy of breast cancer risk assessment combining classic risk factors and breast density. JAMA Oncol. 2018; 4.

13. Chen $\mathrm{L}$, Li Cl, Tang MTC, Porter P, Hill DA, Wiggins $\mathrm{CL}$, et al. Reproductive factors and risk of luminal, HER2-overexpressing, and triple-negative breast cancer among multiethnic women. Cancer Epidemiol. Biomarkers Prev. 2016; 25: 1297-304.

14. Engmann NJ, Golmakani MK, Miglioretti DL, Sprague BL, Kerlikowske K. Population-attributable risk proportion of clinical risk factors for breast cancer. JAMA Oncol. 2017; 3: 1228-36.

15. Sisti JS, Collins LC, Beck AH, Tamimi RM, Rosner BA, Eliassen $\mathrm{AH}$. Reproductive risk factors in relation to molecular subtypes of breast cancer: Results from the nurses' health studies. Int. J. Cancer. 2016; 138: 2346-56.

16. Agurs-Collins T, Ross SA, Dunn BK. The Many Faces of Obesity and Its Influence on Breast Cancer Risk. Front. Oncol. 2019; 9.

17. Sun YS, Zhao Z, Yang ZN, Xu F, Lu HJ, Zhu ZY, et al. Risk factors and preventions of breast cancer. Int. J. Biol. Sci. 2017; 13: 138797.

18. Nasim-Akhtar, Sabiha-Javied, Tufail M. Enhancement of natural radioactivity in fertilized soil of Faisalabad, Pakistan. Environ. Sci. Pollut. Res. 2012; 19: 3327-38.

19. Naeem M, Munir A, Ghani U, Hayat M, Qamar SA, Mehmood T, et al. Risk factors, genetic mutations and prevention of breast cancer Advanced DNA Barcoding View project DNA Barcodes of Different Plants and Protein Analysis View project Risk factors, genetic mutations and prevention of breast cancer International Journal of Biosciences | IJB |. 2019; 14: 492-6.

20. Bukhari MH, Arshad M, Jamal S, Niazi S, Bashir S, Bakhshi IM, et al. Use of Fine-Needle Aspiration in the Evaluation of Breast Lumps. Patholog. Res. Int. 2011; 2011: 1-10.

21. Kamińska M, Ciszewski $T$, Łopacka-Szatan K, Miołła $P$, Starosławska E. Breast cancer risk factors. Prz. Menopauzalny. 2015; 14: 196-202.

22. Makarem N, Chandran U, Bandera E V., Parekh N. Dietary Fat in Breast Cancer Survival. Annu. Rev. Nutr. 2013; 33: 319-48.

23. Harvie M, Howell A, Evans DG. Can Diet and Lifestyle Prevent Breast Cancer: What Is the Evidence? Am. Soc. Clin. Oncol. Educ. B. 2015; 35: e66-73.

24. Thiébaut ACM, Kipnis V, Chang SC, Subar AF, Thompson FE, Rosenberg PS, et al. Dietary fat and postmenopausal invasive breast cancer in the national institutes of health - AARP diet and health study cohort. J. Natl. Cancer Inst. 2007; 99: 451-62.

25. Predná L, Habánová M, Sláviková E, Wyka J. Hormonal contraceptives and hormone replacement therapy as a possible factor of breast cancer. Rocz. Państwowego Zakładu Hig. 2015; 66: 269-74.

26. Tan MM, Ho WK, Yoon SY, Mariapun S, Hasan SN, Shin-Chi Lee $D$, et al. A case-control study of breast cancer risk factors in 7,663 women in Malaysia. PLoS One. 2018; 13.

27. Washbrook E. Risk factors and epidemiology of breast cancer. Women's Heal. Med. 2006; 3: 8-14.

28. Marchbanks PA, McDonald JA, Wilson HG, Folger SG, Mandel MG, Daling JR, et al. Oral contraceptives and the risk of breast cancer. N. Engl. J. Med. 2002; 346: 2025-32.

29. Marchbanks PA, Curtis KM, Mandel MG, Wilson HG, Jeng G, Folger SG, et al. Oral contraceptive formulation and risk of breast cancer. Contraception. 2012; 85: 342-50.

30. Crosignani PG. Breast cancer and hormone-replacement therapy in the Million Women Study. Maturitas. 2003; 46: 91-2.

31. Knight JA, Fan J, Malone KE, John EM, Lynch CF, Langballe R, et al. Alcohol consumption and cigarette smoking in combination:
A predictor of contralateral breast cancer risk in the WECARE study. Int. J. Cancer. 2017; 141: 916-24.

32. Kispert S, McHowat J. Recent insights into cigarette smoking as a lifestyle risk factor for breast cancer. Breast Cancer Targets Ther. 2017; 9: 127-32.

33. Brewer HR, Jones ME, Schoemaker MJ, Ashworth A, Swerdlow AJ. Family history and risk of breast cancer: an analysis accounting for family structure. Breast Cancer Res. Treat. 2017; 165: 193-200.

34. Brozek I, Ratajska M, Piatkowska M, Kluska A, Balabas A, Dabrowska $M$, et al. Limited significance of family history for presence of BRCA1 gene mutation in Polish breast and ovarian cancer cases. Fam. Cancer. 2012; 11: 351-4.

35. Beral V, Bull D, Doll R, Peto R, Reeves G. Breast cancer and breastfeeding: Collaborative reanalysis of individual data from 47 epidemiological studies in 30 countries, including 50302 women with breast cancer and 96973 women without the disease. Lancet. 2002; 360: 187-95.

36. Miglioretti DL, Lange J, Van Den Broek JJ, Lee Cl, Van Ravesteyn NT, Ritley D, et al. Radiation-induced breast cancer incidence and mortality from digital mammography screening a modeling study. Ann. Intern. Med. 2016; 164: 205-14.

37. Norsa'adah B, Rampal KG, Rahmah MA, Naing NN, Biswal BM. Diagnosis delay of breast cancer and its associated factors in Malaysian women. BMC Cancer. 2011; 11: 141.

38. Maas P, Barrdahl M, Joshi AD, Auer PL, Gaudet MM, Milne RL, et al. Breast Cancer Risk From Modifiable and Nonmodifiable Risk Factors Among White Women in the United States. JAMA Oncol. 2016; 2: 1295-302.

\begin{tabular}{|c|c|}
\hline \multicolumn{2}{|c|}{ AUTHORSHIP CONTRIBUTION } \\
\hline Muhammad Mudassar & $\begin{array}{l}\text { Manuscript writing, Data Analysis, } \\
\text { Result Compilation, Discussion, } \\
\text { References Writing }\end{array}$ \\
\hline Muhammad Awais & $\begin{array}{l}\text { Data Collection, Technical Review, } \\
\text { Histopathological Review }\end{array}$ \\
\hline Nadeem Ikram & Literature Review \\
\hline Sadia Hameed & Proof Reading \\
\hline Shazia Aslam & $\begin{array}{l}\text { Histopathology Slides Review, Proof } \\
\text { Reading }\end{array}$ \\
\hline abas Baloch & Proof Reading \\
\hline
\end{tabular}

